\title{
A new paradigm for Aedes spp. surveillance using gravid ovipositing sticky trap and NS1 antigen test kit
}

\author{
Sai Ming Lau ${ }^{1,2}$, Tock H. Chua ${ }^{3}$, Wan-Yussof Sulaiman², Sylvia Joanne², Yvonne Ai-Lian Lim², \\ Shamala Devi Sekaran ${ }^{4}$, Karuthan Chinna ${ }^{5}$, Balan Venugopalan ${ }^{1,6}$ and Indra Vythilingam ${ }^{2^{*}}$
}

\begin{abstract}
Background: Dengue remains a serious public health problem in Southeast Asia and has increased 37-fold in Malaysia compared to decades ago. New strategies are urgently needed for early detection and control of dengue epidemics.

Methods: We conducted a two year study in a high human density dengue-endemic urban area in Selangor, where Gravid Ovipositing Sticky (GOS) traps were set up to capture adult Aedes spp. mosquitoes. All Aedes mosquitoes were tested using the NS1 dengue antigen test kit. All dengue cases from the study site notified to the State Health Department were recorded. Weekly microclimatic temperature, relative humidity $(\mathrm{RH})$ and rainfall were monitored.
\end{abstract}

Results: Aedes aegypti was the predominant mosquito (95.6\%) caught in GOS traps and 23\% (43/187 pools of 5 mosquitoes each) were found to be positive for dengue using the NS1 antigen kit. Confirmed cases of dengue were observed with a lag of one week after positive Ae. aegypti were detected. Aedes aegypti density as analysed by distributed lag non-linear models, will increase lag of 2-3 weeks for temperature increase from 28 to $30{ }^{\circ} \mathrm{C}$; and lag of three weeks for increased rainfall.

Conclusion: Proactive strategy is needed for dengue vector surveillance programme. One method would be to use the GOS trap which is simple to setup, cost effective (below USD 1 per trap) and environmental friendly (i.e. use recyclable plastic materials) to capture Ae. aegypti followed by a rapid method of detecting of dengue virus using the NS1 dengue antigen kit. Control measures should be initiated when positive mosquitoes are detected.

Keywords: GOS traps, Dengue NS1 kit, Aedes mosquito, Surveillance

\section{Background}

Dengue was first reported in Malaysia in the early 1900s [1]. It became endemic in the 1960s and has emerged as a major public health problem in Malaysia from 1973 $[2,3]$ to the new millennium [4]. The two main vectors for dengue transmission in Malaysia are Aedes aegypti and Aedes albopictus, the former being the primary vector associated with dengue outbreaks $[5,6]$ and is also responsible for the transmission of chikungunya virus, yellow fever virus and Zika virus [7, 8]. Dengue has been a serious public health problem in tropical

\footnotetext{
* Correspondence: indra.vythilingam@gmail.com; indrav@um.edu.my ${ }^{2}$ Department of Parasitology, Faculty of Medicine, University of Malaya, Lembah Pantai, 50603 Kuala Lumpur, Malaysia

Full list of author information is available at the end of the article
}

and subtropical countries $[9,10]$ and currently there is a 30-fold increase globally in incidence compared to 50 years ago [11]. In 2015, Zika virus has also become a huge public health problem in the Americas and may spread across the globe $[12,13]$.

The total number of dengue cases in Malaysia has increased 37-fold from 989 in 1973 [14] to 46,171 cases in 2010 [4]. The yearly rate of increase of reported cases rose from $47 \%$ between $2012-2013$ to $62.1 \%$ between 2013-2014 [2012: 20,923 cases (35 deaths); 2013: 40,222 cases (92 deaths); 2014: 103,610 cases (215 deaths)] [15]. In 2015 there were 120,836 cases with 336 deaths [incidence rate, IR, of 396 cases per 100,000 population] where the State of Selangor contributed to the highest IR, of 1,076 cases per 100,000 population. Fatality rate in 
2015 was $0.28 \%$ up from $0.2 \%$ in 2014 . Selangor contributed the highest number of deaths (127) in 2015 (Report of the Communicable Disease control division of Ministry of Health Malaysia; Lau SM, personal communication).

Vector control has been the hallmark of the dengue control programmes in many countries in Southeast Asia [16] as anti-dengue drugs are not yet available. The most recent dengue vaccine is partly efficacious as it falls short of the levels of protection required for a standalone intervention [17]. House to house larval surveys, source reduction, larviciding, fogging, ULV which represent the old paradigms of dengue prevention and eradication are no longer practicable and need to be augmented by more targeted but less ambitious outbreak responses that focus on a few tools that might justify expense of deployment [18]. However, according to recent reports these tools (larval surveys, fogging, ULV) have not really been evaluated for their effectiveness in dengue control $[19,20]$. These methods have been partially effective decades ago because Aedes house index ranged from 4.7 to $58.8 \%$ in the 1980 's [21] to 0.1 to $6.9 \%$ in the $1990 \mathrm{~s}$ [22] and from 1.5 to $2 \%$ in recent years [15].

In the 1960 s to 1980 s the common breeding sites for Aedes in Malaysia were drums, earthenware jars, tires, bathtubs and ant traps [21-23]; however these have been replaced by discreet cryptic places which are more difficult for humans to locate [16]. Recent ecological studies in Penang, north Malaysia [24] showed increased diversity of containers, a shift to outdoor breeding opportunities and outdoor human daytime activities may increase exposure bites and transmission risks. Due to unplanned and increasing urbanisation since the mid-1970s, the control of the vectors has become more challenging [25, 26]. The lack of correlation between larval indices and dengue cases [27] and development of resistance by the Aedes to pyrethroids and temephos insecticides [28-31] pose a serious challenge to dengue control.

Of the control measures currently practised, targeted indoor residual spraying, thermal and ULV fogging are compromised by insecticide resistance and the transient nature of control [32]. Oviposition sites are often small, cryptic and difficult to locate, which makes effective larval control problematic. New paradigms for dengue control such as Release of Insects with Dominant Lethality (RIDL) and Wolbachia to control the Aedes population [33-36] require regulatory and lengthy approval in each country before they can be deployed to the field. In many countries studies are being conducted on the use of sticky traps to lure and trap gravid Aedes female adults [37-44]. These traps come in different designs and some contain insecticides or incorporate pyriproxyfen to kill the progeny $[45,46]$. In a randomised control trial using BG sentinel trap, trapping slightly reduced the density of Aedes in the experimental area compared to the control area [47]. However, in a trial using CDC autocidal gravid trap (AGO) there was a significant reduction in adult Ae. aegypti between 53 to $70 \%$ in the intervention area compared to the control area [48].

Detecting dengue viral antigens from mosquitoes using antigen detection kits even by public health workers with minimum training has been reported [4952]. In a previous study conducted in an urban area in peninsular Malaysia, we showed that the infected Ae. aegypti mosquito was obtained from sticky noninsecticidal traps before the first case was reported [53]. The trap actually targets gravid Aedes mosquitoes which can be infected. The Health Department staff involved in this study also found that it was easier to trap the adult mosquitoes than to carry out labour-intensive larval surveys.

The objective of this study was to evaluate the use of Gravid Ovipositing Sticky (GOS) trap and the NS1 testing system for surveillance of dengue virus transmission in urban Malaysia over a two year period.

\section{Methods}

Study site

The study was conducted in Mentari Court Apartments in the town of Petaling Jaya, State of Selangor (population 5.87 million), the most populated state in Malaysia. The details of the study site were previously described [53]. The study spanned over two years from November 2013 to December 2015 (week 47 in 2013 to week 47 in 2015). Mentari Court Apartments consist of seven blocks of 17 floors each with a total resident population of approximately 12,000 occupying 3,472 residential units.

\section{Trapping of mosquitoes using the GOS trap}

A detailed description of the gravid mosquito ovipositing in sticky trap (GOS trap) was provided in [53]. The cost of each trap is less than USD 1. Briefly a total of 21 traps was deployed in each block (as determined from the pilot study [53]), three each on ground floor (GF), $3^{\text {rd }}$, $6^{\text {th }}, 9^{\text {th }}, 12^{\text {th }}, 15^{\text {th }}$ and $17^{\text {th }}$ floor. The traps were set along the common corridors, 50-100 m apart and were placed near potted plants if available. All traps were filled with 7-day-old hay infusion water. The traps were checked weekly and the water changed during inspection. One ovitrap per floor was also set on the same floors as the GOS traps, mainly for the purpose of checking the presence of the Aedes mosquitoes.

Two teams consisting of two men each checked the traps weekly. Traps were inspected and those with mosquitoes on sticky surface were covered with a lid, placed inside a plastic container and brought back to the laboratory for further processing. If there were no mosquitoes 
the sticky sheets were changed monthly or as required if they were too dirty.

In the laboratory, the mosquitoes were identified morphologically to species. A pair of heat sterilised forceps was used to remove the mosquitoes from the sticky surface to prevent cross contamination. All the abdomens of the Ae. aegypti and Ae. albopictus were pooled (five per pool) for viral antigen detection tests which cost USD 4 per test. The head and thorax were individually stored in Eppendorf tubes at $-80{ }^{\circ} \mathrm{C}$ until processed by RT-PCR to determine dengue virus serotypes.

\section{Detection of dengue viral antigen in pooled mosquitoes}

The SD Bioline NS1 antigen kit (Standards Diagnostic, Gyeonggi-do, Republic of Korea) was used to test for dengue antigen in the pooled mosquito abdomens. In brief, $50 \mu \mathrm{l}$ of PBS was added to the pooled abdomens and homogenised, the lysate was centrifuged briefly and the supernatant was added to the well of the test kit. After a lapse of 10-15 min, the reading was recorded. If two bands were present, the sample was considered positive. For negative samples, only the control band will appear. If the pooled abdomens were positive, the head and thorax of every individual of the pool were tested separately for dengue virus serotypes using multiplex RT-PCR. However, 25 head and thorax (from 5 pools of Ae. aegypti) were not subjected to RT-PCR due to misplacement of samples.

\section{RNA extraction and multiplex RT-PCR}

Individual mosquitoes (head and thorax) were homogenised in pre-chilled Eppendorf tubes with $0.2 \mathrm{ml}$ of growth medium (Minimum Essential Medium, MEM; Biowest, Missouri, USA). The homogenate was then centrifuged at $21,000 \times g$ for $15 \mathrm{~min}$ at $4{ }^{\circ} \mathrm{C}$. RNA extraction was carried out using Cardo pathogen extraction kit (Qiagen, Hilden, Germany) and the kit's protocol was strictly followed. The extracted samples were then subjected to one step multiplex RT-PCR using AccuPower RT-PCR PreMix (Bioneer, Seoul, South Korea) using the protocol of Yong et al. [54]. Briefly, this was a premix in a lyophilised form and was contained in $0.2 \mathrm{ml}$ tubes. Thus, $15 \mu \mathrm{l}$ of primer mix was added to each tube followed by $5 \mu \mathrm{l}$ of the RNA template, vortexed and briefly spun. RT-PCR was performed in a Bio-RAD (Hercules, California, USA) PCR machine. The steps for this assay consisted of a 30 -min RT step at $50{ }^{\circ} \mathrm{C}$, 15 min of Taq polymerase activation at $95{ }^{\circ} \mathrm{C}$, followed by 40 cycles of PCR at $95{ }^{\circ} \mathrm{C}$ denaturation for $30 \mathrm{~s}, 60{ }^{\circ} \mathrm{C}$ of annealing for $30 \mathrm{~s}$ and $72{ }^{\circ} \mathrm{C}$ extension for $1 \mathrm{~min}$. Final extension was $72{ }^{\circ} \mathrm{C}$ for $10 \mathrm{~min}$. Five $\mu \mathrm{l}$ of the PCR product was then analysed by gel electrophoresis.

\section{Dengue case data from Mentari Court Apartments}

Data of serologically confirmed dengue cases (by NS1 or IgM/IgG) from the seven residential blocks were obtained from the Ministry of Health, Malaysia. It is mandatory for all hospitals and private practitioners to report cases to the Ministry of Health. The date of onset of case was used for all data analyses.

\section{Meteorological data}

Data of weekly rainfall was obtained using rain guage RGR126 (Oregon Scientific Inc., Oregon, USA) in the study site. Maximum and minimum measures of temperature and humidity were obtained from the nearest meteorological station located five $\mathrm{km}$ from the study site.

\section{Statistical data analysis}

All statistical analyses were done using weekly data and $\mathrm{R}$ programming language for statistical analysis (version 3.2.4) [55]. Preliminary simple linear and nonlinear correlation analysis indicated a lack of relationship between the environmental factors and total numbers of Aedes trapped, and between NS1-positive mosquito pools and dengue cases, due to lag effect. Subsequently we used the family of distributed lag non-linear models (DLNM), (DLNM package version 2.20 [56], which can simultaneously analyse non-linear factor-response dependencies and delayed effects, and provides an estimate of the overall effect in the presence of delayed contributions [57]. The effect of rainfall and temperature on the total number of Aedes trapped was investigated using the model: glm (Aedes $\sim$ cb.temp + cb.rain, family $=$ quasipoisson(), data); where $\mathrm{cb}=\mathrm{cross}$ basis. For dengue cases, the model is: glm (case $\sim$ cb.total_aegypti + cb.ns1 positive + ns(time, 3) + woy, family = quasipoisson, data) where woy $=$ week of the year. Both the Ae. aegypti trapped per week and cases per week at each trap floor were analysed separately by generalised linear mixed model (GLMM), using the block and floor as fixed factors, and the week as a random factor. Zero inflation and Poisson distribution were incorporated in the analysis. Differences in numbers of Ae. aegypti and cases between blocks and between floors were tested with Tukey's contrasts at $P=0.05$.

\section{Results}

The study site was predominantly an Ae. aegypti (95.6\%) area where 840 female (85\%) and 148 male (15\%) Ae. aegypti were caught compared to 37 female $(80 \%)$ and nine male (20\%) Ae. albopictus. The total number of Ae. aegypti trapped per week was highest in Jan 2014, thereafter the density followed a regular six-monthly pattern of higher numbers indicated by the spline graph, e.g. in June-July 2014, January and June-July 2015, rising again 
towards end of 2015 (Fig. 1a). As for number of cases, there were three peaks in: January 2014, March and August-September 2015 (Fig. 1b). The number of NS1 mosquito pools found positive followed the trend of the total number of trapped Ae. aegypti (Fig. 1c). The number of eggs collected followed the same pattern as the total number of Aedes, but the peaks appeared to decrease with time (Fig. 1d).

The weekly mean temperature fluctuated within a narrow range between $27.6-31{ }^{\circ} \mathrm{C}$ (Fig. 2), and there was no discernible trend in the relationship between temperature and total number of trapped Aedes. However rainfall appears to have some relationship, albeit lagged. The plot of lag-response curves (Fig. 3) for

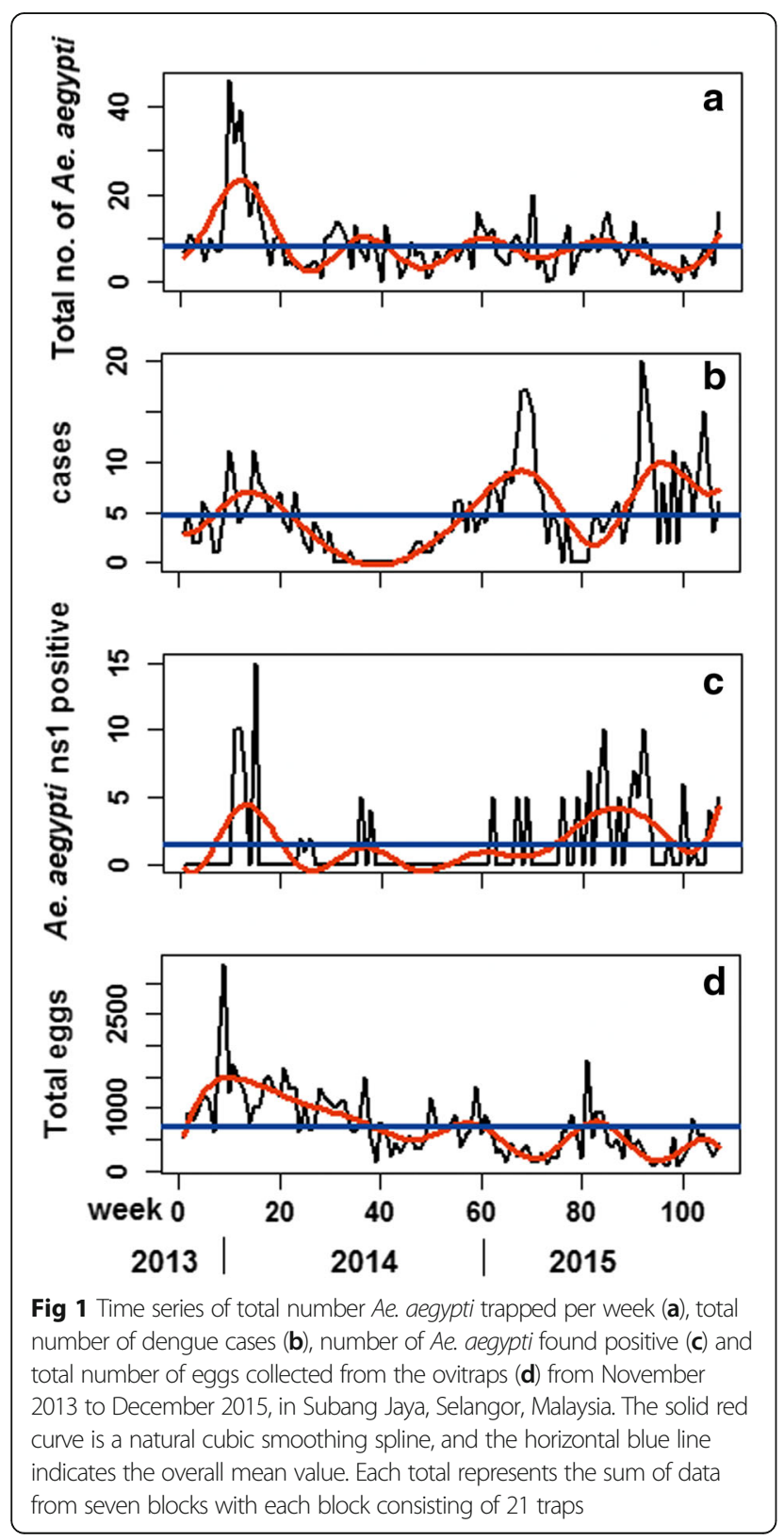

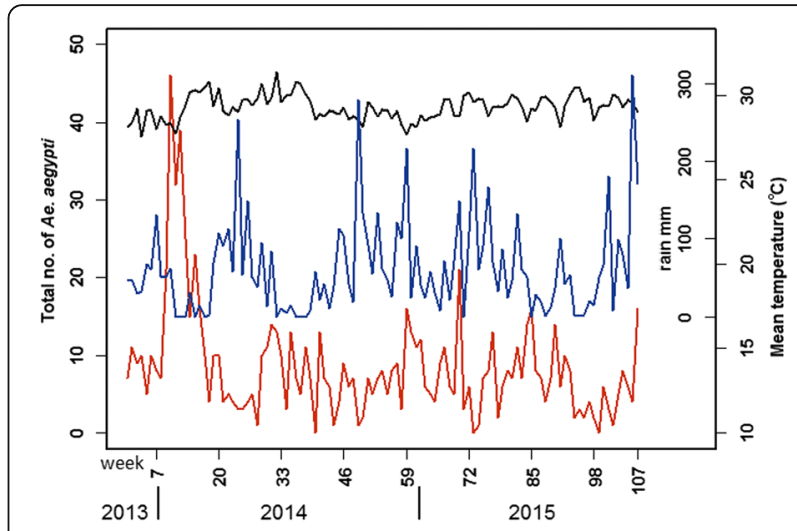

Fig 2 Plot of rainfall, mean temperature and total Aedes aegypti trapped per week in relation to time. Key: red, Ae. aegypti trapped; blue, rain; black, temperature $\left({ }^{\circ} \mathrm{C}\right)$

different temperatures indicated that the number of trapped Aedes will be higher at 2-3-week lag if the temperature increased from 28 to $30{ }^{\circ} \mathrm{C}$. Rainfall appeared to have a negative direct effect on the number of trapped Aedes, but positive effect was observed after the third week (Fig. 4), indicating Aedes number will be higher by a 3-week lag.

Significant difference was detected in the number of trapped Ae. aegypti between block B and E (Table 1). Similarly, Ae. aegypti was trapped more at ground level than any other floor, while $3^{\text {rd }}$ and $17^{\text {th }}$ floors were not different (Additional file 1: Figure S1).

There was no difference in number of dengue cases reported during the study period between the floors, with values ranging 24 (floor 8) to 37 (floor 3). Interesting enough, floor 17 had 32 cases (Additional file 2: Figure S2). However, there was a significant difference between the blocks, with block E and G having the highest number of cases (Table 2; Additional file 3: Figure S3).

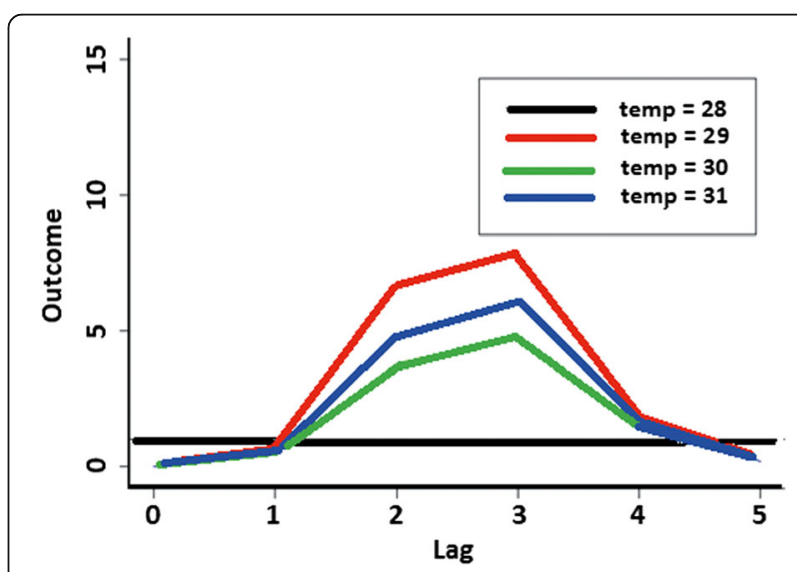

Fig. 3 Lag-response curves of temperatures on weekly total numbers of Aedes aegypti trapped, with reference levels at $28^{\circ} \mathrm{C}$ 


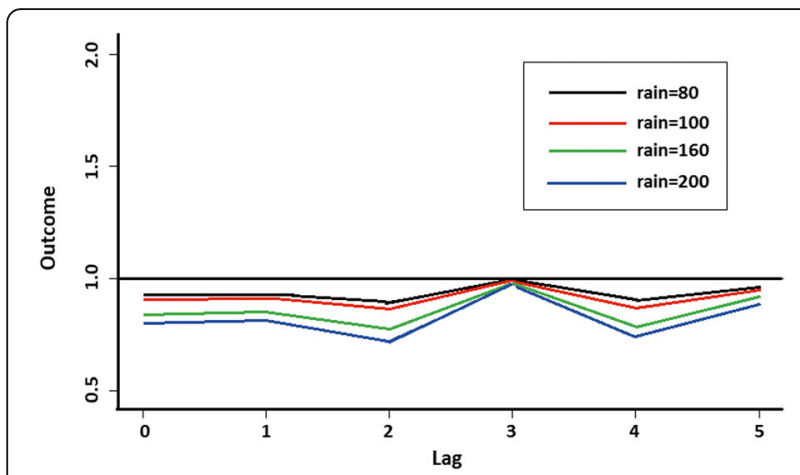

Fig. 4 Lag-response curves of weekly rainfall on total numbers of Aedes aegypti trapped, with reference levels at $20 \mathrm{~mm}$ rainfall (line at 1.0)

The relationship of number of dengue cases with both the number of NS1-positive mosquito pools and lag is depicted in Fig. 5. Cases occurred after a lag of one week after NS1-positive mosquito pool was detected, but peaked at 2 weeks lag. The plot of lag-response curves (Fig. 6) for different numbers of NS1-positive mosquito pools indicates that dengue cases will be highest at 2-3 weeks lag.

Forty-three pools of Ae. aegypti were positive by NS1 giving a minimum infection rate (MIR) of 51.2 per 1,000 (Additional file 4: Table S1). Only three Ae. albopictus pools were positive by NS1 but none of the heads and thoraces were positive by RT-PCR. The RT-PCR results of the individual head and thorax for Ae. aegypti were as follows: DENV1: 3; DENV2: 1; DENV3: 27; DENV2/ DENV3: 3; DENV1/DENV3: 1 . Three pools of mosquito (head and thorax) were negative. This may be due to the fact that the virus was still only incubating in the midgut and had not been disseminated to the salivary glands, or due to degradation of RNA in the mosquitoes. Heads and thoraces of mosquitoes from four negative pools were tested and shown to be negative by RT-PCR (Additional file 4: Table S2).

Table 1 Mean number of Ae. aegypti trapped per week for each block and each floor as predicted by generalised linear mixed model

\begin{tabular}{lclc}
\hline Block & $\begin{array}{c}\text { No. of Ae. aegypti } \\
\text { trapped per week }\end{array}$ & Floor & $\begin{array}{c}\text { No. of Ae. aegypti } \\
\text { trapped per week }\end{array}$ \\
\hline A & $0.3011^{\text {a }}$ & Ground floor & $0.8545^{\text {a }}$ \\
B & $0.2133^{\text {ab }}$ & $3^{\text {rd }}$ floor & $0.3529^{\mathrm{b}}$ \\
C & $0.2530^{a}$ & $6^{\text {th }}$ floor & $0.2969^{\text {bc }}$ \\
D & $0.2531^{a}$ & $9^{\text {th }}$ floor & $0.1697^{c}$ \\
E & $0.4021^{\text {ac }}$ & $12^{\text {th }}$ floor & $0.2678^{c}$ \\
F & $0.3586^{a}$ & $15^{\text {th }}$ floor & $0.2008^{c}$ \\
G & $0.2787^{a}$ & $17^{\text {th }}$ floor & $0.3229^{b}$ \\
\hline
\end{tabular}

Different letters along a column indicate the means are different significantly at $P<0.05$ as tested by Tukey's test
Table 2 Generalised linear mixed model fitting of the dengue cases data for 2013-2015

\begin{tabular}{llc}
\hline Block & Total cases & $\begin{array}{c}\text { Predicted mean per } \\
\text { week for block }\end{array}$ \\
\hline A & 59 & $0.725^{\mathrm{a}}$ \\
B & 53 & $0.621^{\mathrm{a}}$ \\
C & 60 & $0.728^{\mathrm{ab}}$ \\
D & 45 & $0.536^{\mathrm{a}}$ \\
E & 118 & $1.380^{\mathrm{b}}$ \\
F & 65 & $0.778^{\mathrm{ab}}$ \\
G & 109 & $1.294^{\mathrm{b}}$ \\
\hline
\end{tabular}

The model used is of the form "glmm $<-$ glmmadmb (cases $~$ block + floor $+(1 \text { |year), zero Inflation }=\mathrm{T} \text {, data }=\text { data, family }=\text { Poisson })^{\prime}$. Akaike information criterion $(A I C)=1,019.652$. Block means with different superscript letters indicate they are significantly different at $P<0.05$

\section{Discussion}

The increasing burden of dengue in Selangor, Malaysia is daunting and signifies a growing challenge to public health officials. Presently two teams of the health department staff are only able to inspect 40 premises (larval surveys) per day which could be increased to 3,000 premises if they were to use the GOS trap.

The main control strategies for dengue have not changed since their inception in the 1970s. House-to-house Aedes larval surveys followed by source reduction and larviciding remain the main tools for dengue control [16] not only in Malaysia but also in most other countries in Southeast Asia [16]. It has already been

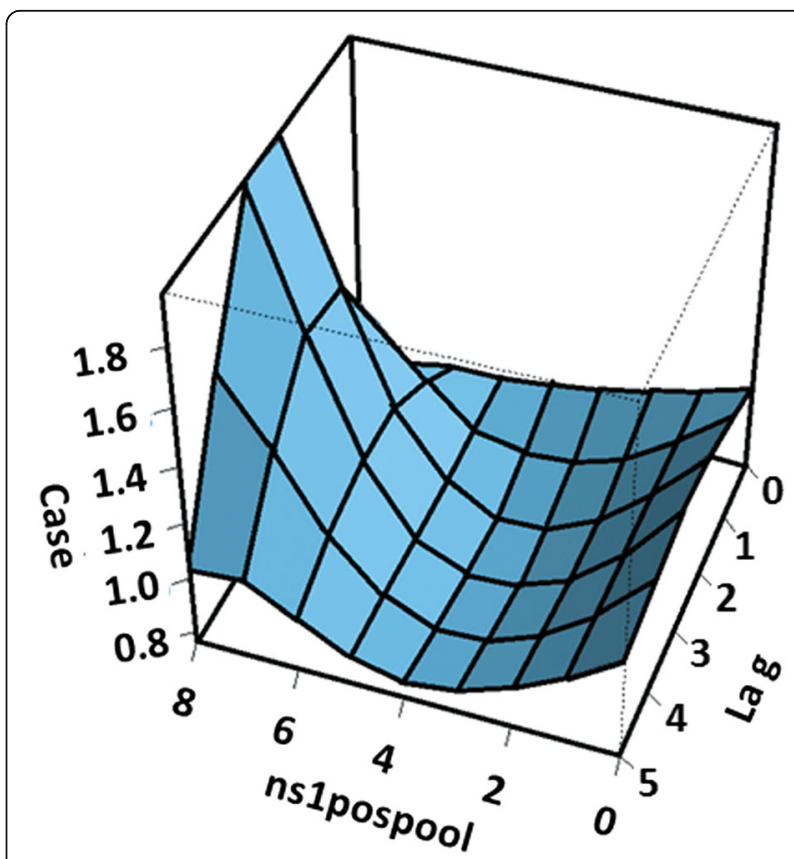

Fig. 5 Three-dimensional plot of cases along NS1-positive mosquitoes and lags, with reference at none NS1-positive detected 


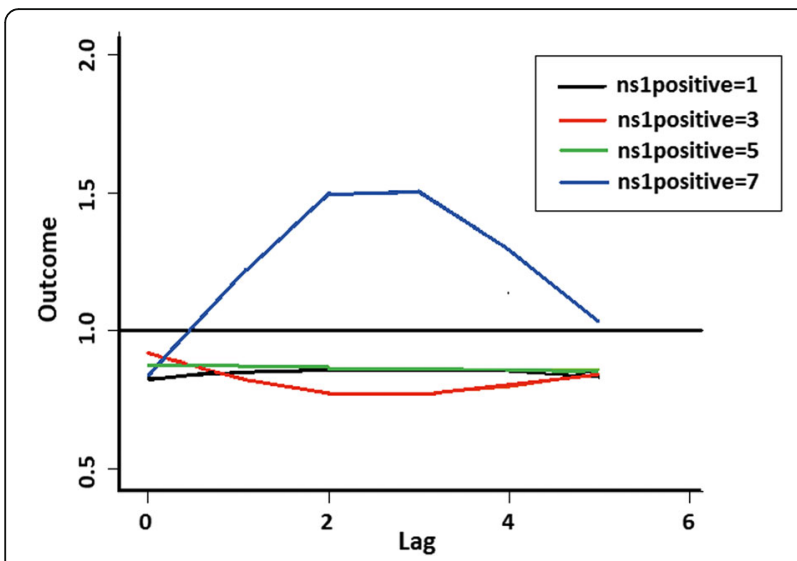

Fig. 6 Plot of lag-response curves for different NS1-positive mosquitoes on dengue cases with reference line in NS1 positive (line at 1.0)

documented that these methods are not effective but they are still being used $[14,35,36]$.

Studies have shown that Ae. aegypti can pick up dengue virus when biting asymptomatic or oligosymptomatic subjects [58] resulting in silent transmission from humans to mosquitoes. This might explain why dengue epidemics are on the rise. The present study indicates that the detection of dengue-positive mosquito will give rise to dengue cases after a lag of one week. This lends credence to our hypothesis that one way forward for dengue surveillance is the use of GOS trap coupled with the use of NS1 antigen kit for the detection of the virus in mosquitoes. Sensitivity of NS1 antigen kit on mosquitoes containing the virus has been established to be high (95\%) [49]. According to Sylvestre et al. [52] the NS1 antigen kit has higher sensitivity compared to the qRTPCR and virus isolation on dried Aedes mosquitoes.

Although the sticky traps may be a good and cheap alternative to trap Ae. aegypti, their ability to suppress Aedes population is variable. In Brazil [47] no reduction in the Aedes population was detected in the treated areas while in Puerto Rico they managed to suppress the Ae. aegypti population [48]. However, a comparative study in parts of Brazil using various traps and comparing them to regular house surveys found that the traps produced better results compared to Aedes house index [59]. Thus it is more important in dengue-prone areas to test the mosquitoes for dengue virus and institute control measures when positive mosquitoes are obtained.

Previous studies have shown that ovitraps were useful indicators for the presence of Aedes mosquitoes [60-62], but the association between ovitraps and dengue cases has not been established. Since a single female Ae. aegypti is likely to deposit the eggs in several containers due to skip oviposition behaviour [63], the ovitrap index is not a useful indicator for surveillance. In our study, there was significant correlation between the number of eggs per ovitrap and the number of adults caught per trap (Additional file 5: Figure S4). However, ovitrapping might not be useful for a surveillance programme because it allows an infected mosquito to lay eggs as well as to continue infecting people. The advantage of the GOS trap is that it traps the gravid mosquito which can then be used for virus detection.

Our data indicate there was no difference between the floors in terms of number of cases, although there were more mosquitoes trapped in lower floors. Aedes aegypti was also found breeding in the water tanks on the roof top which could explain the higher number of $A e$. aegypti on floor 17. Nevertheless, dengue infection can occur in any of the floors.

Several studies had been conducted to determine the correlation between climate changes, dengue cases and adult mosquito abundance in the Asia-Pacific region and in the Americas to provide proactive indicator for dengue surveillance [64-66] with varying results. In this study we also analysed the association between weather and Ae. aegypti abundance at micro- level to determine if it could be used as a surveillance tool for dengue control. We found that if the temperature increased from 28 to $30^{\circ} \mathrm{C}$, the abundance of Ae. aegypti will increase with a lag of two weeks; while after rainfall the increase will be with a lag of three weeks. The shorter lag could be due to higher human density, an environment conducive to mosquito breeding in the study area and global warming. In Bangkok the cases increased two months after a heavy rainfall [67], in Puerto Rico it was confirmed that in areas where rainfall was uniformly distributed there was no correlation between rainfall and Aedes dynamic [66], while in areas where rainfall was more seasonal there was strong correlation with Aedes density and dengue cases [63]. In Singapore the effects of weather (absolute humidity, temperature, rainfall, relative humidity, wind speed) on dengue cases from 2001 to 2009 showed that absolute humidity was the best predictor and indicator for dengue [65].

Taking all these factors into consideration it would be more cost-effective to setup the GOS traps and monitor the adult population for dengue virus. As suggested one way forward is a package of proactive measures that aim to prevent, diminish or eliminate dengue transmission [11]. The study in Thailand using RT-PCR to detect the dengue virus in mosquitoes also showed a positive association between infected Ae. aegypti and dengue-infected children [68]. That study demonstrated the occurrence of an infected mosquito prior to the reporting of the index case(s). It has been stated recently that dengue virus transmission varies from year to year and place to place making vector control interventions difficult [69], thus it is timely for new measures to be introduced for dengue control instead of relying on reactive tools. The 
GOS traps can at least be introduced in hot-spot areas where dengue outbreaks occur. This GOS trap can also be used in public places such as transportation hubs (train stations, bus stops, etc.) recreation areas and commercial areas as viral-positive Aedes have also been obtained from these areas (Lau SM, personal communication).

If this method is adopted, once the positive mosquito has been detected, health department teams could move into action and carry out control measures even before cases are reported. The GOS traps would eliminate gravid female mosquitoes including the infective individuals as they attempt to oviposit inside the traps. Vector control measures targeting the adult mosquitoes will potentially lower vectorial capacity of infected and incubating mosquitoes and reduce mosquito density below a threshold to prevent dengue outbreaks. At the same time people who fall ill will be aware that it might be dengue and may seek treatment early thus preventing mortality. This approach could be considered as a replacement for the laborious, difficult, time-inefficient, insensitive and costly house-to-house larval surveys [69].

\section{Conclusions}

This study has shown that the use of GOS traps and NS1 kit represents one possible way forward to forewarn and reduce dengue outbreaks which are increasing yearly and projecting a global disease burden. For a start the strategy provides early warning system where swift action can be taken by public health workers to reduce dengue outbreaks. High dengue transmission rates across Southeast Asian countries with extensive diversity in population density, climate, and geology may be explained by the infectiousness of asymptomatic cases to Ae. aegypti [58]. The situation is exacerbated due to a long or delayed response time for fogging and ULV space spraying after a case has been reported. The response may be more efficient when timely vector control measures are implemented after the immediate detection of an infected mosquito from the GOS trap. This study has shown that dengue cases will occur after a lag of one week following the detection of a viral-positive mosquito. However, further research especially a randomised control trial should be carried out to evaluate the actual effectiveness of combination of GOS trapping and NS1 antigen testing before it can be integrated into a control programme.

\section{Additional files}

Additional file 1: Figure S1. Percentage of female Ae. aegypti caught in each floor for all seven blocks. (TIF $67 \mathrm{~kb}$ )

Additional file 2: Figure S2. Number of dengue cases recorded during the study period (2013-2015) plotted according to the floor. (TIF $74 \mathrm{~kb}$ )

Additional file 3: Figure S3. Number of dengue cases recorded during the study period (2013-2015) plotted according to the block. (TIF $66 \mathrm{~kb}$ )
Additional file 4: Table S1. Total pools and number of mosquitoes positive by weeks using NS1 Rapid Test Kit. Table S2. Mosquito pools tested by NS1 and RT-PCR. (DOCX $15 \mathrm{~kb}$ )

Additional file 5: Figure S4. Relationship between the weekly numbers of Ae. aegypti caught per trap and number of eggs per ovitrap. There was a significant correlation between the number of eggs per ovitrap (mean 12.66, range 1.52-56.81) and the number of adults caught per trap $(r=0.41, t=4.5$, $d f=105, P<0.001)$. (TIF $1980 \mathrm{~kb})$

\section{Abbreviations}

DLM: Distributed lag linear model; DNLM: Distributed lag non-linear models; GLMM: Generalised linear mixed model; GOS: Gravid ovipositing sticky; IgG: Immunoglobulin G; IgM: Immunoglobulin M; IR: Incidence rate; RTPCR: Reverse transcriptase polymerase chain reaction; ULV: Ultra-low volume

\section{Acknowledgements}

We would like to thank the vector control staff of Selangor Vector Borne Disease Control Programme for their help rendered in the field work. Thanks also to Drs Allan Schapira, and Jeffery Hii formerly of WHO Geneva and WHO WPRO respectively for their constructive comments of the manuscript.

\section{Funding}

This study was funded by University of Malaya student grant PG192-2015A provided to the first author.

\section{Availability of data and materials}

All data are included in the manuscript and in the Additional files 1, 2, 3, 4 and 5 .

\section{Authors' contributions}

IV, LSM, WYWS, YLAL and BV conceived and designed the study, LSM, WYWS and BV were responsible for the field work; LSM carried out laboratory work; SJ and SDS carried out the molecular work; THC, KC and LSM analysed the data; IV, THC, YLAL, LSM and WYWS prepared the manuscript; all other authors were responsible for editorial processing of the manuscript. All authors read and approved the final manuscript.

\section{Competing interests}

The authors declare that they have no competing interests.

\section{Consent for publication}

Director General of Health Malaysia for his permission to publish this article and the National Medical Research Register approval No. is NMRR-13-1725-15193 (IIR)

Ethics approval and consent to participate

Permission was obtained from the residents and management of the Mentari Court Apartments to carry out the study.

\section{Publisher's Note}

Springer Nature remains neutral with regard to jurisdictional claims in published maps and institutional affiliations.

\section{Author details}

${ }^{1}$ Selangor State Health Department, State Vector Borne Disease Control Unit, 29 Jalan Bayu Tinggi, 41200 Klang, Selangor, Malaysia. ²Department of Parasitology, Faculty of Medicine, University of Malaya, Lembah Pantai, 50603 Kuala Lumpur, Malaysia. ${ }^{3}$ Department of Pathobiology and Medical Diagnostics, Faculty of Medicine and Health Sciences, Universiti Malaysia Sabah, Jalan UMS, 88400 Kota Kinabalu, Sabah, Malaysia. ${ }^{4}$ Department of Microbiology, Faculty of Medicine, University of Malaya, Lembah Pantai, 506030 Kuala Lumpur, Malaysia. ${ }^{5}$ Julius Centre, Department of Social and Preventive Medicine, Faculty of Medicine, University of Malaya, Lembah Pantai, 50603 Kuala Lumpur, Malaysia. ${ }^{6}$ Perak State Health Department, Jalan Panglima Bukit Gantung Wahab, 30590 Ipoh, Perak, Malaysia. 


\section{Received: 19 January 2017 Accepted: 16 March 2017} Published online: 21 March 2017

\section{References}

1. Skae F. Dengue fever in Penang. Brit Med J. 1902;2(2185):1581.

2. Shekhar KC, Huat OL. Epidemiology of Dengue/Dengue Hemorrhagic Fever in Malaysia - A retrospective epidemiological study 1973-1987. Part I: Dengue hemorrhagic fever (DHF). Asia-Pacific J Pub Health. 1992;6(2):15-25.

3. Shekhar KC, Huat OL. Epidemiology of dengue/dengue hemorrhagic fever in Malaysia - A retrospective epidemiological study 1973-1987. Part II: Dengue Fever (DF). Asia-Pacific J Public Health. 1992;6(3):126-33.

4. Mohd-Zaki AH, Brett J, Ismail E, L'Azou M. Epidemiology of dengue disease in Malaysia (2000-2012): a systematic literature review. PLoS Negl Trop Dis. 2014;8(11):e3159.

5. Macdonald W. Aedes aegypti in Malaya: II. Larval and adult biology. Ann Trop Med Parasitol. 1956;50(4):399-414.

6. Cheong WH, Rudnick A, Lin T. The vectors of dengue and dengue hemorrhagic fevers in Malaysia. Dengue fever studies in Malaysia. Inst Med Res Bull. 1986;23:155-67.

7. Petersen E, Wilson ME, Touch S, McCloskey B, Mwaba P, Bates M, et al. Rapid spread of Zika virus in the Americas - implications for public health preparedness for mass gatherings at the 2016 Brazil Olympic Games. Int J Infect Dis. 2016;44:11-5.

8. Roth A, Mercier A, Lepers C, Hoy D, Duituturaga S, Benyon E, et al. Concurrent outbreaks of dengue, chikungunya and Zika virus infections-an unprecedented epidemic wave of mosquito-borne viruses in the Pacific 2012-2014. Euro Surveill. 2014;19(41):20929.

9. Sam S-S, Omar SFS, Teoh B-T, Abd-Jamil J, AbuBakar S. Review of dengue hemorrhagic fever fatal cases seen among adults: a retrospective study. PLoS Negl Ttop Dis. 2013;7(5):e2194

10. Gubler DJ. The economic burden of dengue. Am J Trop Med Hyg. 2012;86(5):743-4.

11. Achee NL, Gould F, Perkins TA, Reiner Jr RC, Morrison AC, Ritchie SA, et al. A critical assessment of vector control for dengue prevention. PLoS Negl Trop Dis. 2015;9(5):e0003655.

12. Faria NR, da Silva Azevedo RS, Kraemer MU, Souza R, Cunha MS, Hill SC, et al. Zika virus in the Americas: Early epidemiological and genetic findings. Science. 2016;352(6283):345-9.

13. Yakob L, Walker T. Zika virus outbreak in the Americas: the need for nove mosquito control methods. Lancet Glob Health. 2016;4(3):e148-e9.

14. Wallace HG, Lim TW, Rudnick A, Knudsen AB, Cheong WH, Chew V. Dengue hemmorrhagic fever in Malaysia: the 1973 epidemic. Southeast Asian J Trop Med Public Health.1980;11(11):1-3.

15. Mudin RN. Dengue incidence and the prevention and control program in Malaysia. Int Med J Mal. 2015;14(1):05-10.

16. Chang MS, Christophel EM, Gopinath D, Abdur RM. Challenges and future perspective for dengue vector control in the Western Pacific Region. Western Pac Surveill Response. 2011;2(2):9-16.

17. Capeding MR, Tran NH, Hadinegoro SRS, Ismail HIHM, Chotpitayasunondh T, Chua MN, et al. Clinical efficacy and safety of a novel tetravalent dengue vaccine in healthy children in Asia: a phase 3, randomised, observermasked, placebo-controlled trial. Lancet. 2014;384(9951):1358-65.

18. Ritchie S, Devine G. Conventional vector control: evidence it controls arboviruses, In: Vasilakis N, Gubler DJ, editors. Arboviruses: molecular biology, evolution and control. United Kingdom: Caister Academic Press; 2016

19. Esu E, Lenhart A, Smith L, Horstick O. Effectiveness of peridomestic space spraying with insecticide on denque transmission; systematic review. Trop Med Int Health. 2010;15(5):619-31.

20. Gubler DJ. Dengue and dengue hemorrhagic fever. Clin Microbiol Rev. 1998:11(3):480-96

21. Ho T, Vythilingam I. A preliminary survey of Ae. aegypti in Selangor Peninsular Malaysia. Med J Mal. 1980;24(4):409-14.

22. Sulaiman S, Pawanchee ZA, Arifin Z, Wahab A. Relationship between Breteau and house indices and cases of dengue/dengue hemorrhagic fever in Kuala Lumpur, Malaysia. J Am Mos Control Assoc. 1996;12:494-6.

23. Cheong W. Preferred Aedes aegypti larval habitats in urban areas. Bull World Health Org. 1967;36(4):586.

24. Saifur RG, Dieng $H$, Hassan AA, Salmah MRC, Satho T, Miake F, et al. Changing domesticity of Aedes aegypti in northern peninsular Malaysia: reproductive consequences and potential epidemiological implications. PloS One. 2012:7(2):e30919.

25. Kwa B. Environmental change, development and vectorborne disease: Malaysia's experience with filariasis, scrub typhus and dengue. Environ Develop Sustainability. 2008;10(2):209-17.

26. Mia MS, Begum RA, Er AC, Abidin RDZRZ, Pereira JJ. Trends of dengue infections in Malaysia, 2000-2010. Asian Pacific J Trop Med. 2013;6(6):462-6.

27. Morrison AC, Zielinski-Gutierrez E, Scott TW, Rosenberg R. Defining challenges and proposing solutions for control of the virus vector Aedes aegypti. PLoS Med. 2008;5(3):e68.

28. Koou S-Y, Chong C-S, Vythilingam I, Ng L-C, Lee C-Y. Pyrethroid resistance in Aedes aegypti larvae (Diptera: Culicidae) from Singapore. J Med Entomol. 2014:51(1):170-81.

29. Ponlawat A, Scott JG, Harrington LC. Insecticide susceptibility of Aedes aegypti and Aedes albopictus across Thailand. J Med Entomol. 2005;42(5):821-5.

30. Wan-Norafikah O, Nazni WA, Lee HL, Zainol-Ariffin P, Sofian-Azirun M Permethrin resistance in Aedes aegypti (Linnaeus) collected from Kuala Lumpur, Malaysia. J Asia-Pacific Entomol. 2010;13(3):175-82.

31. Ishak $I H$, Jaal Z, Ranson H, Wondji CS. Contrasting patterns of insecticide resistance and knockdown resistance $(\mathrm{kdr})$ in the dengue vectors Aedes aegypti and Aedes albopictus from Malaysia. Parasit Vectors. 2015;8:181.

32. Marcombe S, Mathieu RB, Pocquet N, Riaz M-A, Poupardin R, Sélior $S$, et al. Insecticide resistance in the dengue vector Aedes aegypti from Martinique: distribution, mechanisms and relations with environmental factors. Plos One. 2012;7(2):e30989.

33. de Valdez MRW, Nimmo D, Betz J, Gong H-F, James AA, Alphey L, et al. Genetic elimination of dengue vector mosquitoes. Proc Natl Acad Sci USA. 2011;108(12):4772-5.

34. Harris AF, McKemey AR, Nimmo D, Curtis Z, Black I, Morgan SA, et al. Successful suppression of a field mosquito population by sustained release of engineered male mosquitoes. Nature Biotechnol. 2012;30(9):828-30.

35. Hoffmann A, Montgomery B, Popovici J, Iturbe-Ormaetxe I, Johnson P, Muzzi F, et al. Successful establishment of Wolbachia in Aedes populations to suppress dengue transmission. Nature. 2011;476(7361):454-7.

36. Frentiu FD, Zakir T, Walker T, Popovici J, Pyke AT, van den Hurk A, et al. Limited dengue virus replication in field-collected Aedes aegypti mosquitoes infected with Wolbachia. PLoS Negl Trop Dis. 2014;8(2):e2688.

37. Chadee DD, Ritchie SA. Efficacy of sticky and standard ovitraps for Aedes aegypti in Trinidad, West Indies. J Vector Ecol. 2010;35(2):395-400.

38. Eiras ÁE, Resende MC. Preliminary evaluation of the" Dengue-MI" technology for Aedes aegypti monitoring and control. Cad Saúde Pública. 2009;25:S45-58.

39. Gama RA, Silva EM, Silva IM, Resende MC, Eiras ÁE. Evaluation of the sticky MosquiTRAP'M for detecting Aedes (Stegomyia) aegypti (L.) (Diptera: Culicidae) during the dry season in Belo Horizonte, Minas Gerais, Brazil. Neotrop Entomol. 2007;36(2):294-302.

40. Lee C, Vythilingam I, Chong C-S, Razak MAA, Tan C-H, Liew C, et al. Gravitraps for management of dengue clusters in Singapore. Am J Trop Med Hyg. 2013:88(5):888-92.

41. Ritchie SA, Long S, Smith G, Pyke A, Knox TB. Entomological investigations in a focus of dengue transmission in Cairns, Queensland, Australia, by using the sticky ovitraps. J Med Entomol. 2004;41(1):1-4.

42. Facchinelli L, Koenraadt CJ, Fanello C, Kijchalao U, Valerio L, Jones JW, et al. Evaluation of a sticky trap for collecting Aedes (Stegomyia) adults in a denque-endemic area in Thailand. Am J Trop Med Hyg. 2008;78(6):904-9.

43. Ritchie SA, Buhagiar TS, Townsend M, Hoffmann A, Van Den Hurk AF, McMahon $\mathrm{L}$, et al. Field validation of the Gravid Aedes Trap (GAT) for collection of Aedes aegypti (Diptera: Culicidae). J Med Entomol. 2014;51(1):210-9.

44. Lorenzi OD, Major C, Acevedo V, Padilla JP, Rivera A, Biggerstaff PJ, et al. Reduced incidence of Chikungunya virus infection in communities with ongoing Aedes Aegypti mosquito trap intervention studies - Salinas and Guayama, Puerto Rico, November 2015-February 2016. MMWR Morb Mortal Wkly Rep. 2016;65. http://dx.doi.org/10.15585/mmwr.mm6518e3.

45. Rapley L, Johnson P, Williams C, Silcock R, Larkman M, Long S, et al. A lethal ovitrap-based mass trapping scheme for dengue control in Australia: II. Impact on populations of the mosquito Aedes aegypti. Med Vet Entomol. 2009;23(4):303-16

46. Harburguer L, Licastro S, Masuh H, Zerba E. Biological and chemical characterization of a new larvicide ovitrap made of plastic with pyriproxyfen incorporated for Aedes aegypti (Diptera: Culicidae) control. J Med Entomol. 2016;53(3):647-52 
47. Degener C, Eiras A, Azara T, Roque R, Rösner S, Codeço C, et al. Evaluation of the effectiveness of mass trapping with BG-sentinel traps for dengue vector control: a cluster randomized controlled trial in Manaus, Brazil. J Med Entomol. 2014:51(2):408-20.

48. Barrera R, Amador M, Acevedo V, Caban B, Felix G, Mackay AJ. Use of the CDC autocidal gravid ovitrap to control and prevent outbreaks of Aedes aegypti (Diptera: Culicidae). J Med Entomol. 2014;51 (1):145-54.

49. Tan C-H, Wong P-SJ, Li M-ZI, Vythilingam I, Ng L-C. Evaluation of the dengue NS1 Ag Strip for detection of dengue virus antigen in Aedes aegypti (Diptera: Culicidae). Vector-Borne Zoon Dis. 2011;11(6):789-92.

50. Voge NV, Sánchez-Vargas I, Blair CD, Eisen L, Beaty BJ. Detection of dengue virus NS1 antigen in infected Aedes aegypti using a commercially available kit. Am J Trop Med Hyg. 2013;88(2):260-6.

51. Muller DA, Frentiu FD, Rojas A, Moreira LA, O'Neill SL, Young PR. A portable approach for the surveillance of dengue virus-infected mosquitoes. J Virol Methods. 2012;183(1):90-3.

52. Sylvestre G, Gandini M, de Araújo JM, Kubelka CF, Lourenço-de-Oliveira R, Maciel-de-Freitas R. Preliminary evaluation on the efficiency of the kit Platelia Dengue NS1 Ag-ELISA to detect dengue virus in dried Aedes aegypti: a potential tool to improve dengue surveillance. Parasit Vectors. 2014;7(1):1.

53. Lau SM, Vythilingam I, Doss JI, Sekaran SD, Chua TH, Sulaiman W, et al. Surveillance of adult Aedes mosquitoes in Selangor, Malaysia. Trop Med Int Health. 2015;20(10):1271-80.

54. Yong Y, Thayan R, Chong H, Tan C, Sekaran S. Rapid detection and serotyping of dengue virus by multiplex RT-PCR and real-time SYBR green RT-PCR. Sing Med J. 2007:48(7):662.

55. Team R. A language and environment for statistical computing. Vienna: $R$ Development Core Team; 2011.

56. Distributed Lag Non-Linear Models [Internet]. 2016. Available from: http:// www.ag-myresearch.com/package-dlnm. Accessed May 2016.

57. Gasparrini A, Armstrong B, Kenward MG. Distributed lag non-linear models. Stat Med. 2010;29(21):2224-34.

58. Duong V, Lambrechts L, Paul RE, Ly S, Lay RS, Long KC, et al. Asymptomatic humans transmit dengue virus to mosquitoes. Proc Ntnl Acd Sci USA. 2015;112(47):14688-93.

59. Codeço CT, Lima AW, Araújo SC, Lima JBP, Maciel-de-Freitas R, Honório NA, et al. Surveillance of Aedes aegypti: Comparison of house index with four alternative traps. PLoS Negl Trop Dis. 2015;9(2):e0003475.

60. Dibo MR, Chierotti AP, Ferrari MS, Mendonça AL, Chiaravalloti NF. Study of the relationship between Aedes (Stegomyia) aegypti egg and adult densities, dengue fever and climate in Mirassol, state of São Paulo, Brazil. Mem Inst Oswaldo Cruz. 2008;103(6):554-60.

61. Focks DA. A review of entomological sampling methods and indicators for dengue vectors. UNDP/World Bank/WHO Special Programme for Research and Training in Tropical Diseases. Geneva: World Health Organisation; 2003. p. 1-40.

62. Dhang CC, Benjamin S, Saranum MM, Fook CY, Lim LH, Ahmad NW, et al. Dengue vector surveillance in urban residential and settlement areas in Selangor, Malaysia. Trop Biomed. 2005;22(1):39-43.

63. Reiter P. Oviposition, dispersal, and survival in Aedes aegypti: implications for the efficacy of control strategies. Vector-Borne Zoon Dis. 2007;7(2):261-73.

64. Barrera R, Amador M, Mackay AJ. Population dynamics of Aedes aegypti and dengue as influenced by weather and human behavior in San Juan, Puerto Rico. PLoS Negl Trop Dis. 2011;5(12):e1378.

65. Xu H-Y, Fu X, Lee LKH, Ma S, Goh KT, Wong J, et al. Statistical modeling reveals the effect of absolute humidity on dengue in Singapore. PLoS Negl Trop Dis. 2014;8(5):e2805.

66. Scott TW, Morrison AC, Lorenz LH, Clark GG, Strickman D, Kittayapong P, et al. Longitudinal studies of Aedes aegypti (Diptera: Culicidae) in Thailand and Puerto Rico: population dynamics. J Med Entomol. 2000;37(1):77-88.

67. Halstead SB. Dengue virus-mosquito interactions. Annu Rev Entomol. 2008:53:273-91.

68. Yoon I-K, Getis A, Aldstadt J, Rothman AL, Tannitisupawong D, Koenraadt $\mathrm{CJ}$, et al. Fine scale spatiotemporal clustering of dengue virus transmission in children and Aedes aegypti in rural Thai villages. PLoS Negl Top Dis. 2012;6(7):e1730.

69. Reiner Jr RC, Achee N, Barrera R, Burkot TR, Chadee DD, Devine GJ, et al. Quantifying the epidemiological impact of vector control on dengue. PLOS Negl Trop Dis. 2016;10(5):e0004588.

\section{Submit your next manuscript to BioMed Central and we will help you at every step:}

- We accept pre-submission inquiries

- Our selector tool helps you to find the most relevant journal

- We provide round the clock customer support

- Convenient online submission

- Thorough peer review

- Inclusion in PubMed and all major indexing services

- Maximum visibility for your research

Submit your manuscript at www.biomedcentral.com/submit 